\title{
Nitric Oxide and the Oxytocin System in Pregnancy
}

\author{
Rungrudee Srisawat, Mike Ludwig, Philip M. Bull, Alison J. Douglas, John A. Russell, and Gareth Leng \\ Department of Biomedical Sciences, University of Edinburgh Medical School, Edinburgh EH8 9XD, United Kingdom
}

We examined the functional role of the nitric oxide (NO)producing system in magnocellular neurons and how this changes at the end of pregnancy, using a combination of blood sampling and oxytocin radioimmunoassay, electrophysiology, immunocytochemistry for Fos expression, and in situ hybridization histochemistry. In urethane-anesthetized virgin rats, systemic administration of NO synthase (NOS) inhibitors led to a facilitation of oxytocin release evoked by hyperosmotic stimulation. Direct application of the NO donor sodium nitroprusside to the supraoptic nucleus by in vivo microdialysis inhibited the electrical activity of both oxytocin neurons and vasopressin neurons, whereas direct application of an NOS inhibitor increased electrical activity, indicating that endogenous $\mathrm{NO}$ acts within the supraoptic nucleus to inhibit neuronal activity. However, during late pregnancy, the influence of endogenous $\mathrm{NO}$ is dramatically downregulated, reflected by a reduced expression of neuronal NOS mRNA in these neurons and a loss of efficacy of NOS inhibitors on stimulus-evoked oxytocin release. This downregulation may cause the oxytocin system to become more excitable at term, resulting in the capacity for greater release of oxytocin during parturition.

Key words: supraoptic nucleus; microdialysis; osmotic stimulation; in situ hybridization; Fos expression; hypothalamus
In pregnancy, stores of oxytocin in the posterior pituitary gland of the rat accumulate in anticipation of secretory demand. The pituitary content increases by $\sim 50 \%$ from the beginning to the end of pregnancy, and this accumulated excess will be released during the 60-90 min of parturition and plays an important role in promoting uterine contraction and birth (Russell and Leng, 1998). Thus, relatively abruptly at the end of pregnancy, the oxytocin system switches from active restraint of secretion (to allow stores to accumulate) to hypersecretion. It is now clear that a number of mechanisms actively contribute to this switch and that these particularly involve the actions of factors secreted from the oxytocin cells themselves. One of these factors, as we describe here, is nitric oxide (NO).

Neuronal nitric oxide synthase (nNOS) is expressed nowhere more densely than in the magnocellular neurosecretory neurons of the supraoptic nuclei (SON) and paraventricular nuclei (PVN). This expression is functionally regulated (Sagar and Ferriero, 1987; Bredt et al., 1990; Pow, 1992; Vincent and Kimura, 1992); increases in nNOS mRNA expression and nicotinamide adenine dinucleotide phosphate (NADPH)-diaphorase staining (a NOS marker) in the SON and PVN (Kadowaki et al., 1994; Villar et al., 1994) and increases in NO-forming activity in the posterior pituitary (Kadowaki et al., 1994) all accompany chronic salt loading.

Most reports suggest that NO is inhibitory to both oxytocin cells and vasopressin cells in the SON and PVN. In electrophysiological studies in vitro, the NO donor sodium nitroprusside (SNP) and the NO precursor L-arginine inhibit supraoptic neurons, whereas the NOS inhibitor $N^{\omega}$-nitro-L-arginine methyl ester (L-NAME) and the NO scavenger hemoglobin enhance neuronal activity (Liu et al., 1997). Application of the NO donor $S$-nitroso- $N$-acetylpenicillamine increases the frequency, but not the amplitude, of spontaneous IPSCs recorded from supraoptic neurons but has no effect on EPSCs (Ozaki et al., 2000). Thus, it has been hypothesized that NO inhibits supraoptic neurons by acting presynaptically at terminals of GABA neurons rather than by a direct effect.

However, a recent report has suggested that NO may be func-

Received March 29, 2000; revised June 12, 2000; accepted June 16, 2000.

This work was supported in part by grants from The Wellcome Trust and the Biotechnology and Biological Sciences Research Council and by a Royal Thai Government scholarship to R.S.

Correspondence should be addressed to Prof. Gareth Leng, Department of Biomedical Sciences, University of Edinburgh Medical School, George Square, Edinburgh EH8 9XD, UK. E-mail: gareth.leng@ed.ac.uk.

Copyright (C) 2000 Society for Neuroscience $0270-6474 / 00 / 206721-07 \$ 15.00 / 0$ tionally excitatory. Yang and Hatton (1999) report that SNP increases dye-coupling among supraoptic neurons and that cGMP, via which $\mathrm{NO}$ is thought to act, excites supraoptic neurons in vitro. These authors speculate that NO may play a role in neuronal hyperexcitability underlying the high-frequency burst firing that is displayed by oxytocin cells in response to suckling (Yang and Hatton, 1999). Such burst firing occurs during parturition and lactation but is never seen in virgin rats, and it is believed that the expression of the ability to discharge in synchronized bursts requires a "remodeling" of the oxytocin cells in the SON and PVN and their inputs, and that this remodeling is driven, indirectly, by the steroid environment of pregnancy (Montagnese et al., 1990).

In this study, we examined the functional role of the NOproducing system in magnocellular neurons and how this changes at the end of pregnancy.

\section{MATERIALS AND METHODS}

Age-matched female Sprague Dawley rats (250-300 gm) were housed under standard laboratory conditions (12 hr dark/light cycle; $22 \pm 1^{\circ} \mathrm{C}$ ) with access to food and water ad libitum. Pregnant rats were obtained by leaving virgin rats with stud males overnight; day 0 of pregnancy was determined by the appearance of a vaginal plug of semen shed into the mating cage. The rats were then housed individually with food and water ad libitum. In these conditions, rats normally gave birth on the afternoon of day 22 of pregnancy.

All studies were on rats anesthetized with urethane (ethyl carbamate, 1.2 $\mathrm{gm} / \mathrm{kg}$, i.p.) or, for studies of Fos expression, with sodium pentobarbitone (Sagatal; 50 mg/kg, i.p; Rhône Mérieux, Hertfordshire, UK).

Blood sampling. Blood samples of $0.3 \mathrm{ml}$ were withdrawn from the left femoral artery via a polythene cannula and heparinized. The plasma was separated by centrifugation and stored at $-20^{\circ} \mathrm{C}$. The blood cells were resuspended in isotonic saline $(0.15 \mathrm{M} \mathrm{NaCl})$ at the same volume as the plasma taken and returned via the left femoral vein. Plasma $\left[\mathrm{Na}^{+}\right]$was determined using a Corning (Corning, NY) 455 flame photometer.

Radioimmunoassay. On the day of assay, plasma samples were thawed and centrifuged. Oxytocin radioimmunoassay was performed using the specific anti-oxytocin antiserum (Higuchi et al., 1985). All samples in each experiment were measured in a single assay to avoid interassay variance.

Intravenous injections were administered via a cannula in the left femoral vein. All drugs were made up in isotonic saline, and control rats were given equivalent volumes of isotonic saline alone.

Effect of NOS inhibitors and SNP on oxytocin release. In experiment 1, virgin rats were injected intraperitoneally with either $N^{\omega}$-nitro-L-arginine (L-NNA) (10 mg/kg; Sigma, Poole, UK) or isotonic saline. In experiment 2 , rats were injected intraperitoneally with either L-NAME $\mathrm{HCl}$ (50 $\mathrm{mg} / \mathrm{kg}$; Sigma) or isotonic saline. Both L-NNA and L-NAME compete with $\mathrm{L}$-arginine for binding the arginine-binding site of NOS. After $4 \mathrm{hr}$, rats were injected intravenously with cholecystokinin (CCK) $(20 \mu \mathrm{g} / \mathrm{kg}$, cholecystokinin-(26-33)-sulfated; Bachem Ltd., Saffron Walden, Essex, UK), 
followed by $4 \mathrm{ml} / \mathrm{kg} 1.5 \mathrm{M} \mathrm{NaCl}$, intraperitoneally. Blood samples were collected before and after each injection.

In a further experiment, a guide cannula was inserted stereotaxically into a lateral cerebral ventricle, at least $2 \mathrm{hr}$ before blood sampling before and after intraperitoneal hypertonic saline as above, for infusion of SNP $(10 \mathrm{nmol} / \mu \mathrm{l}: 5 \mu \mathrm{l}$ at $2 \mu \mathrm{l} / \mathrm{min}$ and then $20 \mu \mathrm{l}$ at $0.7 \mu \mathrm{l} / \mathrm{min}$; Sigma) or vehicle, starting with the intraperitoneal injection.

The effect of $L-N N A$ on Fos expression in rats treated with low doses of hypertonic saline. Virgin rats were pretreated with either L-NNA (10 $\mathrm{mg} / \mathrm{kg}$, i.p.) or vehicle (isotonic saline). After $4 \mathrm{hr}$, the rats were injected intraperitoneally with $2 \mathrm{ml} / \mathrm{kg}$ of either $1.5 \mathrm{M} \mathrm{NaCl}$ or isotonic saline and were decapitated $90 \mathrm{~min}$ later. The brains were frozen and stored at $-70^{\circ} \mathrm{C}$. Frozen coronal sections $(15 \mu \mathrm{m})$ were cut, fixed in $4 \%$ paraformaldehyde in $0.1 \mathrm{M}$ phosphate buffer (PB) $\mathrm{pH} 7.3-7.4$ for $30 \mathrm{~min}$, and washed in $0.1 \mathrm{M}$ PB. Endogenous peroxidase was blocked with hydrogen peroxide solution $0.3 \%$, with methyl alcohol $20 \%$ for $15 \mathrm{~min}$. The slides were then washed with PB-T (0.1 M PB containing 0.3\% Triton X-100). Nonspecific binding was blocked by preincubation with $1 \%$ normal sheep serum for $1 \mathrm{hr}$. The sections were then incubated with a polyclonal antibody raised in rabbits against rat Fos (c-fos Ab-2; Oncogene Sciences, Uniondale, NY) at 1:1000 in preincubation buffer containing $1 \%$ normal sheep serum. After $48 \mathrm{hr}$, the sections were washed with PB-T and incubated for $24 \mathrm{hr}$ with goat anti-rabbit IgG-peroxidase complex (Vector Laboratories, Orton Southgate, UK) at 1:1000 in buffer containing 1\% normal sheep serum. The sections were washed with PB-T, rinsed with 0.1 $\mathrm{M}$ acetate buffer, and incubated with glucose oxidase-Ni diaminobenzidine (DAB) (Sigma) solution. The reaction was terminated with stop solution $(0.1 \mathrm{M}$ acetate buffer). The sections were then rinsed and dehydrated through serial concentrations of ethanol (70,90, 95, and twice in 100\%) and then into xylene before being coverslipped.

In a subsequent experiment, to test the effectiveness of L-NNA against a higher dose of hypertonic saline, virgin rats were pretreated with L-NNA $(10 \mathrm{mg} / \mathrm{kg}$, i.p.) or vehicle (isotonic saline). After $4 \mathrm{hr}$, rats were injected intraperitoneally with $4 \mathrm{ml} / \mathrm{kg} 1.5 \mathrm{M} \mathrm{NaCl}$. After $90 \mathrm{~min}$, the rats were perfused transcardially with isotonic saline, followed by $4 \%$ paraformaldehyde in $0.1 \mathrm{M} \mathrm{PB}, \mathrm{pH} 7.4$. The brains were post-fixed for $2-5 \mathrm{hr}$, cryoprotected in $30 \%$ sucrose in fixative overnight at $4^{\circ} \mathrm{C}$, and then left in $30 \%$ sucrose in $\mathrm{PB}$ at $4^{\circ} \mathrm{C}$ until they sank. Brains were then sectioned coronally $(50 \mu \mathrm{m})$ on a freezing microtome. Free-floating sections were washed in PB-T, endogenous peroxidase was deactivated, and nonspecific staining was blocked as above. The sections were incubated for $48 \mathrm{hr}$ in $\mathrm{Ab}-2$ Fos antibody and then in 1\% biotinylated anti-rabbit immunoglobulin (Vector Laboratories) and 3\% normal goat serum in PB-T for $1 \mathrm{hr}$, and then washed in PB-T (three times for 10 min each) and incubated in ABC complex solution (2\% avidin DH and $2 \%$ biotinylated horseradish peroxidase in PB-T; Vector Laboratories) for $1 \mathrm{hr}$. The sections were then washed in PB-T, rinsed with $0.1 \mathrm{M}$ acetate buffer, and incubated with glucose oxidase-Ni DAB solution for $10 \mathrm{~min}$. The reaction was terminated with stop solution, and sections were rinsed with $\mathrm{PB}$, mounted serially, and left to dry. The sections were then dehydrated as above.

The role of $N O$ in the electrical activity of oxytocin and vasopressin cells. A femoral vein and the trachea were cannulated, and the pituitary stalk and right SON were exposed transpharyngeally as described in detail previously (Leng and Dyball, 1991). Briefly, this surgery involves exposure of the sphenoid bone and the lateral wing of the palatine bone after cautery of the soft palate at the roof of the mouth. A small burr hole is drilled in the sphenoid bone above the neural stalk. To expose the SON, a portion of the bone overlying the trigeminal nerve is removed, and the nerve bundle, which lies between that and the dura overlying the SON, is dissected away. A U-shaped dialysis probe (membrane length, $2.0 \mathrm{~mm}$; Spectra/Por RC Hollow Fibers, Spectrum Medical Inc., Great Falls, MT) was bent to position the loop of the membrane flat onto the exposed ventral glial lamina of the SON after removal of the meninges. A glass micropipette (filled with $0.15 \mathrm{M} \mathrm{NaCl}, 20-40 \mathrm{M} \Omega$ ) was introduced into the center of the loop to record the extracellular activity of single neurons in the SON (Ludwig and Leng, 1997). A bipolar stimulating electrode (SNEX-200X; Clarke Electromedical Instruments, Reading, UK) was placed on the pituitary stalk and set to deliver single matched biphasic pulses $(1 \mathrm{msec},<$ $\mathrm{mA}$ peak to peak) for antidromic identification of supraoptic neurons. Neurons were identified as oxytocin cells by a transient excitation and as vasopressin cells by no effect or short-term inhibition after intravenous injection of $20 \mu \mathrm{g} / \mathrm{kg} \mathrm{CCK}$ (Renaud et al., 1987). The firing rates of cells were recorded using Spike2 software (Cambridge Electronic Design, Cambridge, UK). Artificial CSF (aCSF), pH 7.2 (in mM: NaCl 138, KCl 3.36, $\mathrm{NaHCO}_{3} 9.52, \mathrm{Na}_{2} \mathrm{HPO}_{4} 0.49$, urea 2.16 , and $\mathrm{MgCl}_{2} 1.18$ ) was dialyzed at $3 \mu \mathrm{l} / \mathrm{min}$ throughout the experiment. During recording, dialysis fluid was changed to aCSF containing SNP $(10 \mathrm{~mm}, 100 \mathrm{~mm})$, L-arginine $(100 \mathrm{~mm}$; Sigma), or L-NNA $(10 \mathrm{~mm})$. The concentrations of drugs in the dialysate are considerably in excess of those achieved in the extracellular fluid. From previous experiments that established the dialysis concentration of tetrodotoxin needed to block spike activity in magnocellular neurons, we can estimate that the concentrations achieved within the main body of the SON by dialysis of the ventral zone are approximately three orders of magnitude lower (Ludwig and Leng, 1997).

The effect of NOS inhibitors and naloxone in late pregnancy. Age-matched virgin and day 22 pregnant rats were injected with L-NNA $(10 \mathrm{mg} / \mathrm{kg}$, i.p. or isotonic saline. Four hours later, the rats were injected intraperitoneally with hypertonic saline (virgin, $4 \mathrm{ml} / \mathrm{kg} 1.5 \mathrm{M} \mathrm{NaCl}$, i.p.; pregnant, $5 \mathrm{ml} / \mathrm{kg}$ $2 \mathrm{M} \mathrm{NaCl}$ ). Because plasma $\left[\mathrm{Na}^{+}\right]$is reduced in pregnancy, the volume given to pregnant rats was greater than that given to virgin rats to produce a similar elevated plasma $\left[\mathrm{Na}^{+}\right]$. Naloxone hydrochloride $(5 \mathrm{mg} / \mathrm{kg}$; Sigma) was injected intravenously $40 \mathrm{~min}$ after the hypertonic saline. Plasma samples were collected before and after each injection.

The effect of NOS inhibitors on oxytocin release after intravenous infusion of hypertonic saline in late pregnancy. Age-matched virgin and day 22 pregnant rats were injected intraperitoneally with L-NNA $(10 \mathrm{mg} / \mathrm{kg})$ or isotonic saline. Four hours later, the rats were inf used intravenously with $2 \mathrm{ml}$ of hypertonic saline over $1 \mathrm{hr}(2 \mathrm{M} \mathrm{NaCl}$ in virgin rats and $2.6 \mathrm{M} \mathrm{NaCl}$ in pregnant rats). The different concentrations were chosen after pilot experiments had indicated that these would produce a similar plasma $\left[\mathrm{Na}^{+}\right]$in virgin and pregnant rats at the end of the inf usion. Blood samples were collected before, and every 10 min during, the infusion.

NOS $m R N A$ expression in the SON and PVN in pregnancy. Age-matched virgin, $16 \mathrm{~d}$ pregnant, and $22 \mathrm{~d}$ pregnant rats were decapitated in the morning, and parturient rats were decapitated $2 \mathrm{hr}$ after the birth of the first pup. The brains were frozen on dry ice and stored at $-70^{\circ} \mathrm{C}$. Coronal sections $(15 \mu \mathrm{m})$ were cut on a cryostat, thaw-mounted onto gelatin-coated RNase-free slides, and stored at $-70^{\circ} \mathrm{C}$. Three 45 -mer antisense oligonucleotide probes were used, complementary to bases 223-267 (5'-noncoding region), 4714-4758 (3'-noncoding region) and 1662-1706 of the rat nNOS sequence (Bredt et al., 1991), and labeled at the $3^{\prime}$ end with $\left[\alpha^{-}{ }^{35}\right.$ S $]$ deoxyATP (NEN, Boston, MA) using terminal deoxynucleotidyl transferase (Amersham Pharmacia Biotech, Little Chalfont, UK). The probe-specific activities were $482-1753 \mathrm{Ci} / \mathrm{mmol}$.

Sections were fixed at room temperature with $4 \%$ paraformaldehyde in $0.1 \mathrm{M} \mathrm{PB}, \mathrm{pH} 7.4$, for $30 \mathrm{~min}$, rinsed, and washed in $0.1 \mathrm{M}$ PBS, followed by acetylation in triethylamine solution $(0.25 \%$ acetic anhydride in $0.1 \mathrm{M}$ triethylamine $-0.15 \mathrm{M} \mathrm{NaCl}$ ) for $10 \mathrm{~min}$ to increase tissue permeability. The sections were then dehydrated through 70, 80, 95, and $100 \%$ ethanol, delipidated in chloroform, and partially rehydrated in $95 \%$ ethanol. After air-drying, the slides were placed in a humidified chamber. The sections were hybridized for $17 \mathrm{hr}$ at $37^{\circ} \mathrm{C}$ in $40 \mu \mathrm{l}$ of hybridization buffer [ $4 \times \mathrm{SSC}$, $50 \%$ formamide, $1 \times$ Denhardt's solution, $500 \mu \mathrm{g} / \mathrm{ml}$ sheared salmon sperm DNA (Sigma), $10 \%$ dextran sulfate, and $0.3 \%$ mercaptoethanol] containing ${ }^{35} \mathrm{~S}$-labeled NOS oligonucleotide probes at $2500 \mathrm{dpm} / \mu \mathrm{l}$. The slides were stringently washed in SSC at $55^{\circ} \mathrm{C}$, dipped in $300 \mathrm{~mm}$ ammonium acetate, $70 \%$ ethanol, air-dried, placed in autoradiographic cassettes, and exposed to Hyperfilm- $\beta$ max autoradiography film (Amersham Pharmacia Biotech) with ${ }^{35} \mathrm{~S}$ brain paste standards. The films were exposed for 3 weeks at $4^{\circ} \mathrm{C}$, developed, and fixed. The sections were then dipped in Ilford G-5 emulsion and exposed for 4-5 weeks and then developed and fixed. The sections were then counterstained with cresyl violet, dehydrated in a graded ethanol series, and coverslipped.

The nNOS mRNA was assessed by silver grain density of autoradiographic films, quantified $(5 \times$ and $10 \times$ objective) using the NIH Image analysis system version 1.58 . The density per unit area was obtained by subtracting background measurements over adjacent tissue from each specific tissue measurement and dividing by the area measurements. A logarithmic relationship was plotted for radioactivity against the grain density of the standards. Acceptable grain density values lay on the straight portion of the curve. For each rat, the mean grain density per unit area was calculated for each brain region, and the group means were calculated.

Statistical analysis. All data are reported as means \pm SEM. Data were analyzed statistically by $t$ test, one-way ANOVA, and two-way ANOVA for comparison differences between groups, a one-way repeated measures ANOVA for differences with time, and a two-way repeated measures ANOVA for differences between groups followed by Dunnett's method or Student-Newman-Keuls method. The paired $t$ test and the Wilcoxon signed rank test were used for comparing differences between, before, and after treatments within groups.

\section{RESULTS}

\section{Effect of NOS inhibitors and an NO donor on oxytocin secretion in virgin rats}

Urethane-anesthetized rats were injected intraperitoneally with the NOS inhibitors L-NNA or L-NAME, or isotonic saline, followed by CCK and hypertonic saline to stimulate the secretion of oxytocin (Fig. 1). Hypertonic saline injections lead to a sustained activation of both oxytocin and vasopressin cells, and this activation involves both intrinsic osmoreceptivity of the magnocellular neurons and inputs arising from anterior, periventricular structures. In contrast, intravenous injection of CCK activates oxytocin cells transiently and selectively via a noradrenergic projection from the brainstem (Leng et al., 1999).

The NOS inhibitors alone had no significant effect on the basal plasma $\left[\mathrm{Na}^{+}\right]$or the basal plasma oxytocin concentration. After intravenous injection of CCK, the plasma concentration of oxytocin increased in all rats, and this response was similar in rats pretreated with L-NNA or L-NAME and their respective control 


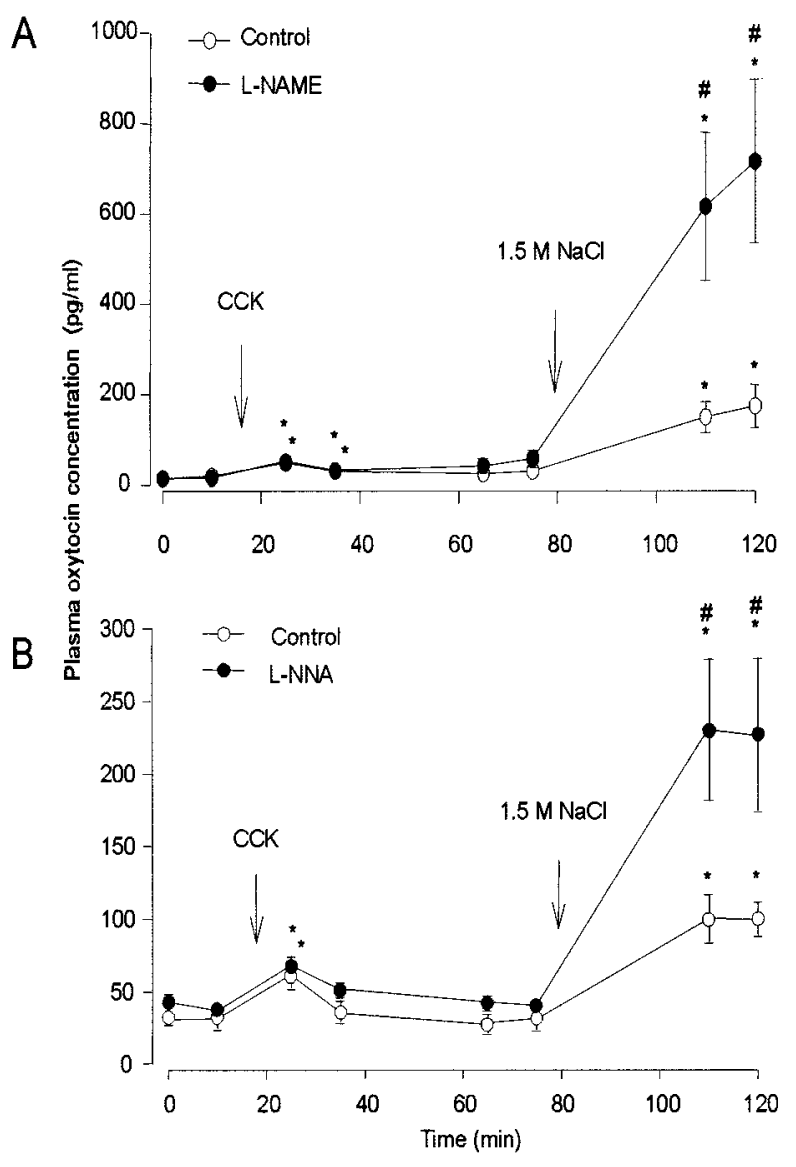

Figure 1. Plasma oxytocin concentration in virgin rats injected with CCK $(20 \mu \mathrm{g} / \mathrm{kg}$, i.v. $)$ and hypertonic saline $(4 \mathrm{ml} / \mathrm{kg} 1.5 \mathrm{M} \mathrm{NaCl}$, i.p. $)$ after pretreatment with L-NAME $(A)$ or L-NNA $(B)$, or vehicle controls. Note that L-NAME and L-NNA significantly enhanced oxytocin secretion evoked in response to hypertonic saline but not secretion evoked by CCK. Data are means \pm SEM $; n=6-8$ rats per group; ${ }^{*} p<0.05$ compared with basal; \#p $<0.05$ compared with controls.

groups. Injection of hypertonic saline produced a much larger increase in the concentration of oxytocin in all rats, and strikingly, the oxytocin release was significantly greater in rats pretreated with either L-NNA or L-NAME than in their respective control groups $(p<0.05)$ (Fig. 1). In a converse experiment, intracerebroventricular infusion of SNP $(250 \mathrm{nmol}$ in $25 \mu \mathrm{l})$ for $30 \mathrm{~min}$ after an intraperitoneal injection of $1.5 \mathrm{M} \mathrm{NaCl}(4 \mathrm{ml} / \mathrm{kg})$ significantly reduced the hyperosmotic stimulation of oxytocin secretion compared with intracerebroventricular vehicle-inf used controls. In the latter, plasma oxytocin concentration at $60 \mathrm{~min}$ after hypertonic saline had increased to $228.9 \pm 51.0 \mathrm{pg} / \mathrm{ml}$ from a basal $56.4 \pm 9.3$ $\mathrm{pg} / \mathrm{ml}(n=8)$, but after intracerebroventricular SNP infusion, plasma oxytocin concentration increased to only $105.1 \pm 25.9$ $\mathrm{pg} / \mathrm{ml}(n=6 ; p<0.05$ vs intracerebroventricular vehicle) from a basal value similar to controls.

Thus, L-NNA and L-NAME had no significant effect on the basal release of oxytocin or on CCK-evoked oxytocin release but potentiated the release evoked by intraperitoneally injected hypertonic saline, suggesting that endogenous NO exercises a restraining influence on the secretion of oxytocin evoked by intense osmotic stimulation. The effects of the NO donor SNP, given by intracerebroventricular inf usion, demonstrated the further capacity of exogenous NO to inhibit osmotically stimulated oxytocin secretion.

The effect of L-NNA on Fos expression in the SON and PVN in rats treated with hypertonic saline

In pentobarbitone-anesthetized rats injected intraperitoneally with $2 \mathrm{ml} / \mathrm{kg} 1.5 \mathrm{M} \mathrm{NaCl}$, Fos immunoreactivity was seen in neuronal

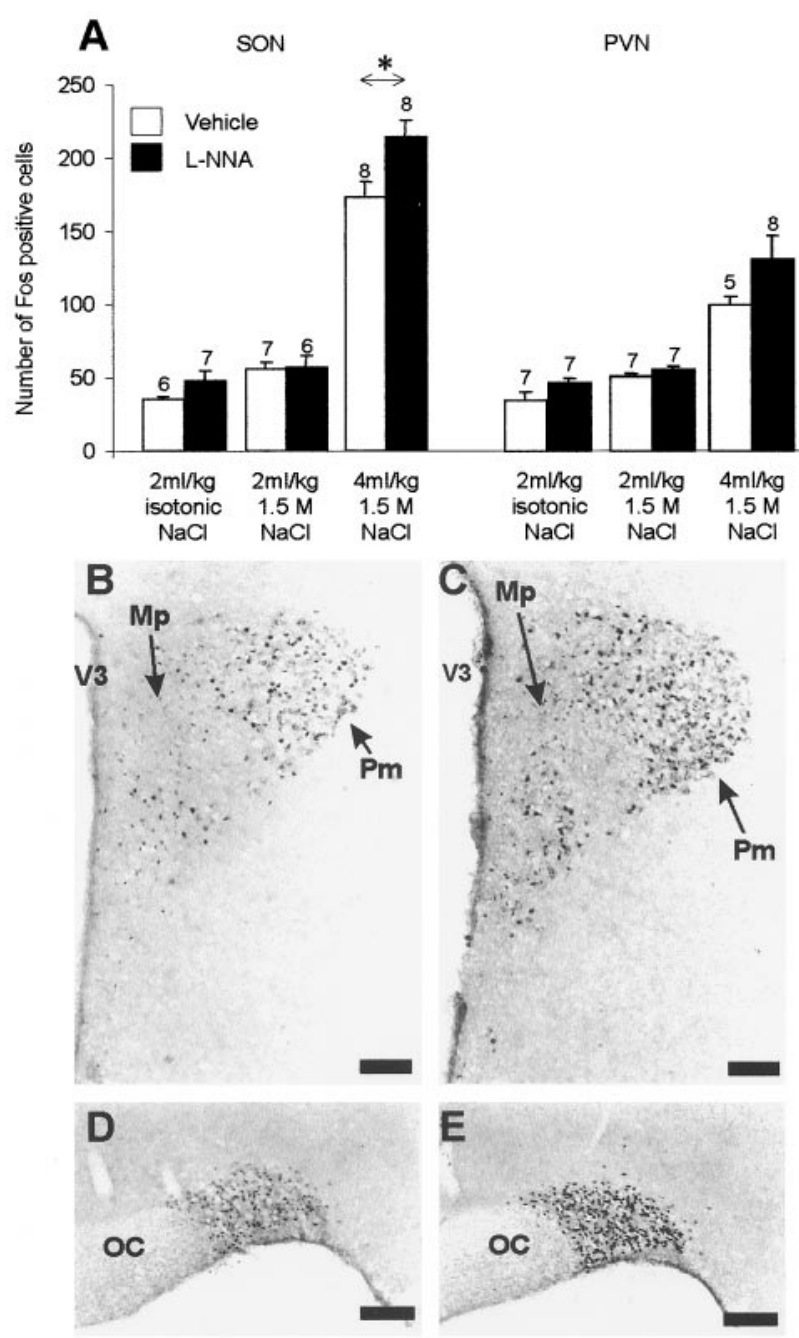

Figure 2. Expression of Fos in the SON and PVN of rats pretreated with L-NNA or vehicle, followed by intraperitoneal injection of either isotonic saline or 2 or $4 \mathrm{ml} / \mathrm{kg} 1.5 \mathrm{M} \mathrm{NaCl}(A)$. Note that a significant increase in the number of Fos-positive neurons was observed in the SON of L-NNApretreated rats compared with vehicle-pretreated rats after intraperitoneal administration of the higher dose of hypertonic saline. Data are means \pm SEM; numbers of rats are above bars; ${ }^{*} p<0.05$ compared with controls. $B-E$, Photomicrographs of Fos expression $90 \mathrm{~min}$ after intraperitoneal injection of $4 \mathrm{ml} / \mathrm{kg} 1.5 \mathrm{M} \mathrm{NaCl}$ in the PVN $(B, C)$ and $\operatorname{SON}(D, E)$ in L-NNA-pretreated rats $(C, E)$ and vehicle-pretreated controls $(B, D) . M p$, Medial parvocellular; $P m$, posterior magnocellular; $O C$, optic chiasm; V3, third ventricle. Scale bars, $100 \mu \mathrm{m}$.

nuclei of magnocellular neurons of the SON and PVN in both L-NNA-pretreated and vehicle-pretreated rats and was primarily absent from surrounding areas of the hypothalamus (Fig. 2). The expression was significantly greater than in control rats injected with isotonic saline $(p<0.05)$ but did not differ significantly between L-NNA-pretreated and vehicle-pretreated rats. In contrast, in rats injected intraperitoneally with a higher dose of hypertonic saline ( $4 \mathrm{ml} / \mathrm{kg} 1.5 \mathrm{M} \mathrm{NaCl})$, more SON cells expressed Fos in L-NNA-pretreated rats than in vehicle-pretreated rats (Fig. 2) (24\% increase; $p<0.05)$. A similar proportional increase in expression was observed in the magnocellular PVN, but this did not reach statistical significance.

Thus, the Fos expression induced in the SON after intraperitoneal injection of a large dose of hypertonic saline was enhanced by L-NNA, whereas L-NNA had no effect on Fos induced by a lesser osmotic stimulus, indicating that the enhancement of stimulated oxytocin release after L-NNA (Fig. 1) reflects, at least in part, increased responsiveness of oxytocin cells to strong stimulation. 



Figure 3. Effects of local application of SNP, L-arginine, and L-NNA on activity of vasopressin and oxytocin neurons. $A-C$, Retrodialysis of SNP onto the SON inhibited the electrical activity of oxytocin $(A)$ and vasopressin $(B)$ neurons, repeatedly and dose-dependently (SNP1, $10 \mathrm{mM}$; SNP2, $100 \mathrm{mM}$ ). $C$, A significant decrease in the activity quotient and the burst length of phasic vasopressin neurons was observed after retrodialysis of $100 \mathrm{~mm} \mathrm{SNP.}{ }^{*} p<0.05 ; n=5$ at 0 and $15 \mathrm{~min}$ and 4 at $45 \mathrm{~min}$, respectively. $D$, Inhibition of a continuously firing putative vasopressin neuron during administration of L-arginine. $E$, L-NNA administered over $60 \mathrm{~min}$ induced an increase in the firing rate of this vasopressin neuron, identified by its inhibitory response to intravenous CCK.

\section{$\mathrm{C}$ \\ 产}

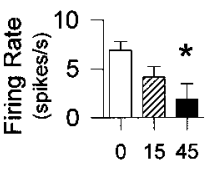

\section{The influence of NO on the electrical activity of oxytocin and vasopressin cells}

Single neurons, antidromically identified as projecting to the posterior pituitary, were recorded from the SON of urethaneanesthetized rats while drugs were administered to the nucleus by retrodialysis. In the above experiments with systemic NOS inhibitors or intracerebroventricular inf usion of an NO donor, the effects on osmotically stimulated oxytocin secretion could result from NO actions at several key sites in the osmoreceptor complex regulating magnocellular neurons. The in vivo electrophysiology studies were designed to test $\mathrm{NO}$ actions in the immediate vicinity of the magnocellular neurons. The spontaneous firing rate of both oxytocin cells and vasopressin cells was inhibited by retrodialysis of SNP in a dose-dependent manner (Fig. $3 A-C$ ). During retrodialysis of $100 \mathrm{~mm} \mathrm{SNP}$, the spontaneous firing rate of four oxytocin cells decreased by $3.01 \pm 1.11$ spikes/sec (98\% decrease), and that of 12 continuously firing vasopressin cells decreased by $7.01 \pm 0.63$ spikes/sec (97\% decrease). In each of four phasically firing vasopressin cells, retrodialysis of $100 \mathrm{~mm} \mathrm{SNP}$ onto the SON for $45 \mathrm{~min}$ caused a significant decrease of firing rate, which involved a decrease in intraburst firing rate, but was principally a consequence of reduced burst length and longer silences evident as reduced activity quotient (time active/time silent; $p<0.05$ ) (Fig. 3C). After 45 min of SNP administration, the mean firing rate was decreased by $4.38 \pm 1.62 \mathrm{spikes} / \mathrm{sec}(73 \%$ decrease $)$, the mean burst length was decreased by $115.01 \pm 65.16$ spikes/sec (93\% decrease), and the activity quotient of these phasic vasopressin cells was decreased by $0.58 \pm 0.20$ ( $72 \%$ decrease).

The inhibition of neuronal activity by SNP was thus similar for oxytocin cells and vasopressin cells and was dose-dependent. Pooling data for oxytocin and vasopressin cells, the mean inhibition of firing rate in response to dialysis of $10 \mathrm{~mm}$ SNP (approximately three orders of magnitude above predicted extracellular concentration; see Materials and Methods) was $50 \pm 9.6 \%(n=6)$; in response to $50 \mathrm{~mm} \mathrm{SNP}$, cells were inhibited by $86 \pm 5.5 \%(n=10)$, and in response to $100 \mathrm{~mm} \mathrm{SNP}$ by $91 \pm 3.7 \%(n=16)$.

Six cells (two oxytocin cells and four vasopressin cells) were recorded during dialysis infusion of L-arginine, and all were inhibited during the infusion by a mean of $2.44 \pm 0.84$ spikes/sec (34\% decrease) (Fig. 3D). Conversely, the firing rates of both oxytocin cells and vasopressin cells increased after local administration of L-NNA (Fig. $3 E$ ). The mean firing rate of five oxytocin cells increased by $0.83 \pm 0.20$ spikes/sec ( $13 \%$ increase), and the mean firing rate of 12 vasopressin cells increased by $1.78 \pm 0.36$ spikes/sec (18\% increase) after retrodialysis of $10 \mathrm{~mm}$ L-NNA.

Thus, endogenous local NO restrains the electrical activity of both oxytocin cells and vasopressin cells in vivo.

\section{The effect of NOS inhibition on hypertonic saline- stimulated oxytocin release in late-pregnant rats}

The similarity of the enhancement of oxytocin release in response to hypertonic saline by blockade of NOS with L-NNA to that after blockade of opioid receptors with naloxone (Russell et al., 1995) prompted us to investigate the relationship between these two mechanisms and to study the role of $\mathrm{NO}$ at the end of pregnancy when the opioid system in the neural lobe is downregulated (Leng et al., 1997).

Anesthetized adult virgin rats and late-pregnant rats were pretreated with L-NNA or isotonic saline and then given an intraperitoneal injection of hypertonic saline. The virgin rats were given 4 $\mathrm{ml} / \mathrm{kg} 1.5 \mathrm{M} \mathrm{NaCl}$ and the pregnant rats were given $5 \mathrm{ml} / \mathrm{kg} 2 \mathrm{M}$ $\mathrm{NaCl}$ to produce similar changes in plasma $\left[\mathrm{Na}^{+}\right]$in the two groups. The basal plasma $\left[\mathrm{Na}^{+}\right]$and oxytocin concentrations were similar in the groups pretreated with L-NNA or isotonic saline. The plasma $\left[\mathrm{Na}^{+}\right]$was increased after intraperitoneal injection of hypertonic saline in all rats, to a similar extent in rats pretreated with L-NNA or isotonic saline (data not shown). In all rats, oxytocin release was increased $30 \mathrm{~min}$ after injection of hypertonic saline. Again, in virgin rats, this response was significantly greater in rats pretreated with L-NNA than in controls $(p<0.05)$. In contrast, in late-pregnant rats, pretreatment with L-NNA had no significant effect. Thus, the effectiveness of the endogenous NO system is functionally downregulated in late-pregnant rats (Fig. 4).

Intravenous injection of naloxone significantly enhanced osmotically induced oxytocin release in all rats (Fig. 4). In virgin rats, the plasma concentration of oxytocin increased by $734 \pm 80 \mathrm{pg} / \mathrm{ml}$ in rats pretreated with L-NNA $(n=15)$ and by $335 \pm 37 \mathrm{pg} / \mathrm{ml}$ in controls $(n=15)$ (difference significant at $p<0.001)$. In latepregnant rats, the plasma concentration of oxytocin increased by $401 \pm 102 \mathrm{pg} / \mathrm{ml}$ in rats pretreated with L-NNA and by $337 \pm 80$ $\mathrm{pg} / \mathrm{ml}$ in controls $(n=15, \mathrm{NS})$. Naloxone increases oxytocin release by potentiating stimulus-secretion coupling (Russell et al., 1995); hence, its effect should be related to the oxytocin release rate prevailing before naloxone administration. The proportionate enhancement of oxytocin secretion was greater in virgin rats than in pregnant rats (average of 6.5-fold enhancement of group means in virgin rats vs 3.7 -fold enhancement in pregnant rats, for rats pretreated with isotonic saline), consistent with the previously described downregulation of opioid restraint at the end of pregnancy. In pregnant rats pretreated with L-NNA, the proportionate enhancement of secretion by naloxone after L-NNA (4.4-fold enhancement) was similar to that in pregnant rats pretreated with vehicle. In contrast, in virgin rats pretreated with L-NNA, the average enhancement by naloxone was 10 -fold, significantly higher than in virgin controls $(p<0.05$, Dunnett's test, allowing for multiple comparisons, after one-way ANOVA on ranks showed significant differences among groups at $p=0.002$ ). 


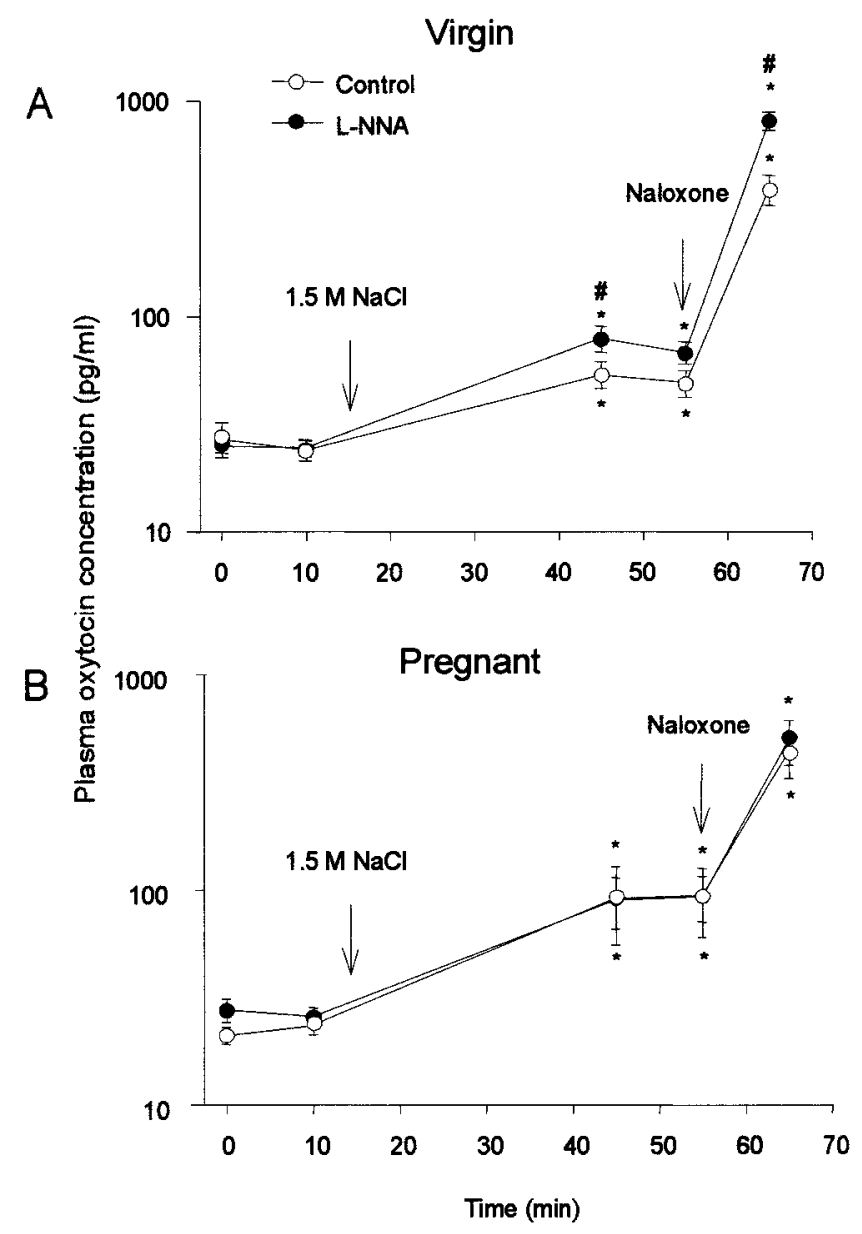

Figure 4. Plasma oxytocin concentration (shown on a log scale) in response to hyperosmotic stimulation and naloxone $(5 \mathrm{mg} / \mathrm{kg}$, i.v. $)$ in virgin ( $A)(1.5 \mathrm{M} \mathrm{NaCl} ; 4 \mathrm{ml} / \mathrm{kg}$, i.p. $)$ or pregnant $(B)(2 \mathrm{M} \mathrm{NaCl} ; 5 \mathrm{ml} / \mathrm{kg}$, i.p. $)$ rats pretreated with either L-NNA or isotonic saline. Oxytocin secretion was enhanced by pretreatment with L-NNA in virgin rats but not in pregnant rats. Means \pm SEM; $* p<0.05$ compared with basal; $\# p<0.05$ between groups.

Thus, in virgin rats, the restraining influence of endogenous NO on oxytocin release induced by intense electrical activation of oxytocin cells is independent of the known autoinhibitory opioid influence on oxytocin release, because the effectiveness of L-NNA is apparent after opioid receptor blockade.

\section{The effect of NOS inhibitor on oxytocin secretion after intravenous infusion of hypertonic saline in late pregnancy}

As well as elevating plasma osmolality, intraperitoneal injection of hypertonic saline produces peritoneal irritation, which may contribute to stimulation of oxytocin secretion by activation of afferent nociceptive pathways (Verbalis et al., 1986). To circumvent this, we administered hypertonic saline via intravenous infusion.

Pretreatment with L-NNA had no significant effect on the basal plasma $\left[\mathrm{Na}^{+}\right]$or oxytocin concentration in either virgin or latepregnant rats. In all rats, plasma $\left[\mathrm{Na}^{+}\right]$gradually increased throughout the course of the hypertonic saline intravenous infusion, with no significant differences between groups. In all rats, the release of oxytocin increased in parallel with the increase in $\left[\mathrm{Na}^{+}\right]$. The increase in L-NNA-treated virgin rats was significantly greater than in control rats. In contrast, in late-pregnant rats, pretreatment with L-NNA had no significant effect (Fig. 5).

Thus, these experiments confirmed that, in virgin rats, endogenous NO restrains oxytocin release induced by hyperosmotic activation of oxytocin cells and confirmed that this restraint is functionally downregulated in late pregnancy.



Figure 5. Plasma oxytocin concentration during intravenous inf usion at 2 $\mathrm{ml} / \mathrm{hr}$ of hypertonic saline in virgin $(A)(2 \mathrm{M} \mathrm{NaCl})$ or pregnant $(B)(2.6 \mathrm{M}$ $\mathrm{NaCl})$ rats pretreated with L-NNA or vehicle. Oxytocin secretion was enhanced by pretreatment with L-NNA in virgin rats but not in pregnant rats. Changes in plasma sodium concentrations (insets) were not different between the groups. Data are means \pm SEM; ${ }^{*} p<0.05$ compared with basal; \#p $<0.05$ compared with controls.

\section{NOS gene expression in the SON and PVN in pregnancy}

Age-matched virgin, $16 \mathrm{~d}$ pregnant, $22 \mathrm{~d}$ pregnant, and parturient rats were used to study nNOS mRNA expression. There were strong hybridization signals for nNOS mRNA over the SON, the magnocellular region of the PVN, the subfornical organ (SFO), and the medial amygdaloid nucleus (AMG). The silver grain density over the SON of $22 \mathrm{~d}$ pregnant rats was significantly less than in the other groups (Fig. 6), with no significant differences for the PVN, SFO, or AMG (data not shown). No significant differences were observed in $16 \mathrm{~d}$ pregnant and parturient rats compared with virgin rats. Inspection of emulsion-dipped sections revealed silver grains distributed over most, if not all, neuronal somata in the SON, consistent with expression in both vasopressin cells and oxytocin cells as described previously (Luckman et al., 1997), with few in the ventral glial zone or perinuclear zone of the SON.

Thus, the functional downregulation of the endogenous NO restraint of oxytocin release shown above is paralleled by a downregulation of NOS mRNA expression, specifically in neurons of the $\mathrm{SON}$, at the end of pregnancy.

\section{DISCUSSION}

The present results demonstrate that the NO donor SNP, applied locally to the SON, inhibits the electrical activity of both oxytocin cells and vasopressin cells, and central administration of SNP strongly inhibited the hyperosmotic stimulation of oxytocin secretion. Conversely, systemic administration of the NOS inhibitors L-NNA or L-NAME had little effect on the basal release of oxytocin but, in virgin rats, enhanced the secretion of oxytocin in conditions of strong stimulation. This enhancement derives, at least in part, from enhanced excitation of the magnocellular neurons, as revealed by Fos expression, and by electrophysiological studies, from an enhancement of the discharge rate of oxytocin 


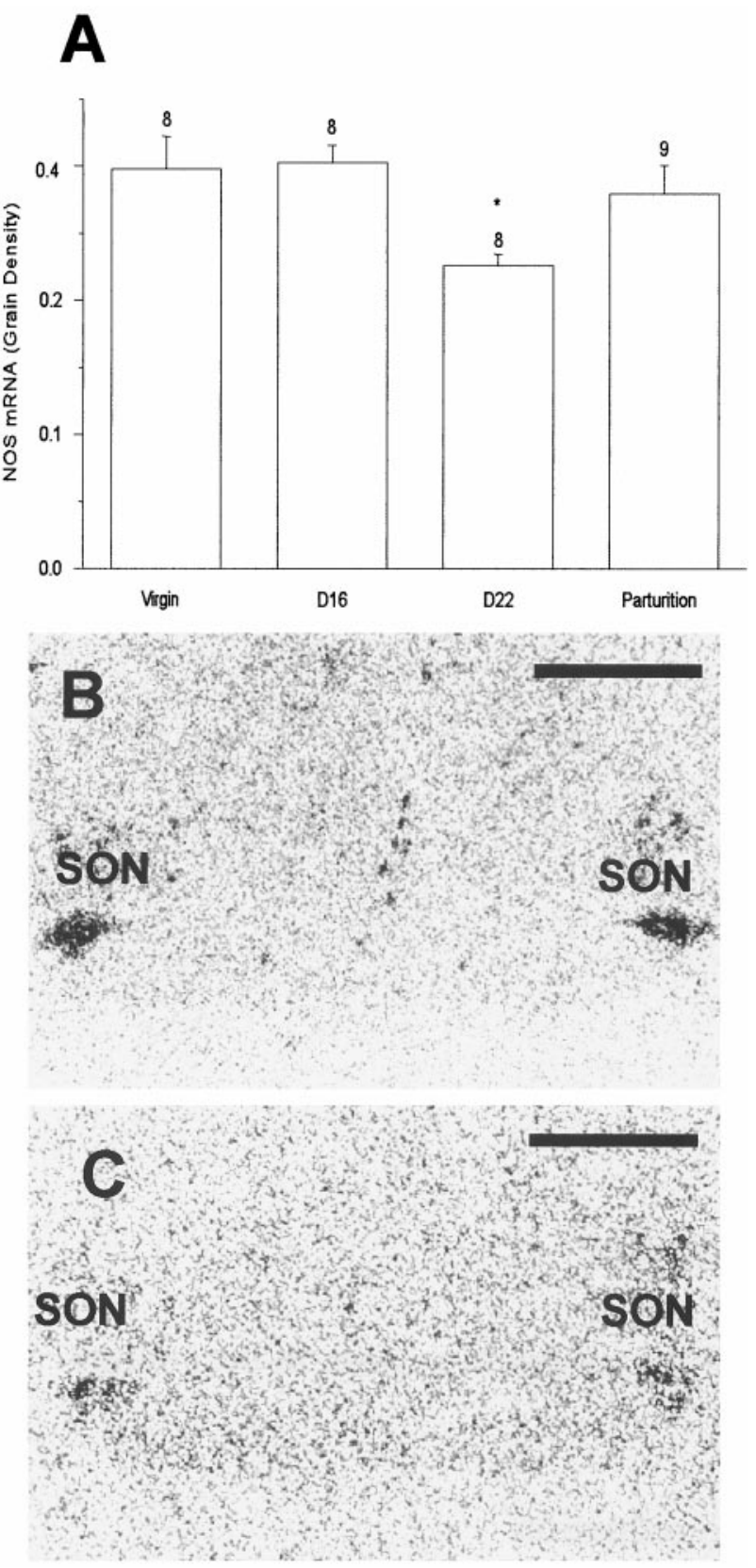

Figure 6. Neuronal NOS mRNA expression measured as film grain density over the SON $(A)$. A significant decrease in nNOS mRNA expression was observed in late-pregnant rats (day 22), but not virgin, day 16, or parturient rats. Data are means \pm SEM; $* p<0.05$. Film autoradiographs of sections hybridized with a ${ }^{35} \mathrm{~S}$ oligonucleotide probe against rat neuronal NOS mRNA in $16 \mathrm{~d}(B)$ and $22 \mathrm{~d}(C)$ pregnant rats. Scale bar, $1 \mathrm{~mm}$.

cells. These findings suggest that NO, produced by oxytocin cells in conditions of strong electrical activity, is an inhibitory feedback regulator of electrical activity. The evidence for an involvement of $\mathrm{NO}$ only during relatively intense activation may suggest that either functionally significant release of NO only occurs above a threshold level of intracellular calcium increase or the actions of NO are only significant above a threshold concentration achieved during intense activity.

Importantly, however, inhibitors of NOS were not effective in late-pregnant rats, suggesting that, at the end of pregnancy, there is a functional downregulation of this feedback mechanism. This downregulation coincided with a downregulation of NOS mRNA expression in the SON on day 22 of pregnancy and was not seen on day 16 of pregnancy. These findings are consistent with the data reported by Okere and Higuchi (1996), who found fewer NADPH- diaphorase-positive cells in the SON and PVN and a decrease in NOS activity in the posterior pituitary in 19-21 d pregnant and parturient rats but not in mid-pregnant rats. Luckman et al. (1997) also reported no change in nNOS mRNA expression in either the SON or the PVN in mid-pregnancy. In contrast, other authors have reported that the number of NADPH-diaphorase-positive cells in the SON and PVN is increased in mid-pregnant rats (Popeski et al., 1999) and 22 d pregnant rats (Woodside and Amir, 1996; Popeski et al., 1999), and one study (Popeski et al., 1999) has reported an upregulation of both nNOS protein and nNOS mRNA expression in the hypothalamus of $20 \mathrm{~d}$ pregnant rats assessed by Western blot and Northern blot, respectively (Xu et al., 1996). It may be that the timing of measurements is critically important; the last $48 \mathrm{hr}$ of pregnancy is a period in which there are major fluctuations in the ovarian steroid milieu and in the activity of the oxytocin system.

After the decrease in expression in late pregnancy, we observed an acute increase in expression in the SON during parturition (significant increase from late pregnancy levels). This indicates that the activation of oxytocin cells during parturition may be associated with stimulation of nNOS mRNA expression. Indeed, it is possible that the level of NOS expression in the SON may follow the level of electrical activity of the oxytocin cells; it is believed that the level of activity in oxytocin cells is low $\sim 1 \mathrm{~d}$ before parturition, when the oxytocin cells are inhibited by a centrally acting opioid system (Douglas et al., 1995). Their activity increases when oxytocin receptor expression increases in the uterus, a few hours before the first delivery, when these receptors complete a positive feedback loop between oxytocin release and uterine contraction. Whereas nNOS mRNA expression appears to be acutely upregulated during parturition itself, the lag before protein translation is likely to mean that the functional consequences of this upregulation are for lactation rather than parturition itself.

In conclusion, in virgin rats, the endogenous NOS system has a potent restraining influence on oxytocin cell excitability. During late pregnancy, this influence is functionally downregulated. This is likely to cause the oxytocin system to become more excitable at term, resulting in the capacity for greater release of oxytocin during parturition. Conversely, reimposition of NO inhibition by central SNP infusion impedes parturition (Okere et al., 1996).

Two other phenomena have been described that would complement this downregulation. First, the secretion of oxytocin from the nerve terminals in the posterior pituitary is restrained by the cosecretion of dynorphin, acting via $\kappa$ receptors on the oxytocin nerve terminals. This opioid auto-inhibition is upregulated in midpregnancy, contributing to an accumulation of oxytocin stores in the posterior pituitary at this time, but, like the NO system described here, is downregulated at term pregnancy (Leng et al., 1997). Second, the major extrinsic restraining influence on the electrical activity of oxytocin cells is thought to be exerted by GABA. A high proportion of all terminals that synapse onto oxytocin cells contain GABA, and both the number of GABAcontaining synapses and the constitution of the postsynaptic GABA receptor itself change by the end of pregnancy (Fenelon and Herbison, 1996). The principal consequence of the observed change in $\mathrm{GABA}_{\mathrm{A}}$ receptor subunit composition appears to be that, as the concentration of progesterone in the circulation falls at the end of pregnancy, the duration of GABA-mediated IPSPs also falls, leading to an increase in the excitability of oxytocin cells (Brussaard et al., 1997). In view of the proposed presynaptic excitatory action of NO on GABA terminals in the SON (Horn et al., 1994; Ozaki et al., 2000), these changes in GABA receptors would be potentiated by the downregulation of NOS.

How a selective downregulation of nNOS mRNA expression occurs in the SON in late pregnancy deserves consideration. We cannot safely conclude that there is no similar downregulation in the PVN; the data show a strong tendency in the same direction, and this may be masked by nNOS expression in parvocellular neurons. However, it seems intrinsically unlikely that genomic regulation of nNOS in magnocellular neurons is substantially different from that in the amygdala or SFO, for example, in which no 
such trend was evident. Possibly the simplest interpretation is that nNOS expression is regulated in concert with electrical activity, as either a consequence of electrical activity per se or a consequence of intracellular mechanisms activated by the synaptic inputs that drive increased electrical activity. Thus, the downregulation of nNOS mRNA expression in late pregnancy described here might reflect the electrical quiescence of oxytocin cells in the last day of pregnancy described by Summerlee (1981).

Thus, several mechanisms act in concert on oxytocin cells at the end of pregnancy to contribute to both an increased excitability of oxytocin cells and an increased releasability of oxytocin from the nerve terminals.

\section{REFERENCES}

Bredt DS, Hwang PM, Snyder SH (1990) Localization of nitric oxide synthase indicating a neural role for nitric oxide. Nature 347:768-770.

Bredt DS, Hwang PM, Glatt CE, Lowenstein C, Reed RR, Snyder SH (1991) Cloned and expressed nitric oxide synthase structurally resembles cytochrome P-450 reductase. Nature 351:714-718.

Brussaard AB, Kits KS, Baker RE, Willems WA, Leyting-Vermeulen JW, Voorn P, Smit AB, Bicknell RJ, Herbison AE (1997) Plasticity in fast synaptic inhibition of adult oxytocin neurons caused by switch in GABA(A) receptor subunit expression. Neuron 19:1103-1114.

Douglas AJ, Neumann I, Meeren HKM, Leng G, Johnstone LE, Munro G, Russell JA (1995) Central endogenous opioid inhibition of supraoptic oxytocin neurons in pregnant rats. J Neurosci 15:5049-5057.

Fenelon VS, Herbison AE (1996) Plasticity in GABA(A) receptor subunit mRNA expression by hypothalamic magnocellular neurons in the adult rat. J Neurosci 16:4872-4880.

Higuchi T, Honda K, Fukuoka T, Negoro H, Wakabayashi K (1985) Release of oxytocin during suckling and parturition in the rat. J Endocrinol 105:339-346.

Horn T, Smith PM, McLaughlin BE, Bauce L, Marks GS, Pittman QJ, Ferguson AV (1994) Nitric oxide actions in paraventricular nucleus: cardiovascular and neurochemical implications. Am J Physiol 266:R306-R313.

Kadowaki K, Kishimoto J, Leng G, Emson PC (1994) Up-regulation of nitric oxide synthase (NOS) gene expression together with NOS activity in the rat hypothalamo-hypophysial system after chronic salt loading: evidence of a neuromodulatory role of nitric oxide in arginine vasopressin and oxytocin secretion. Endocrinology 134:1011-1017.

Leng G, Dyball RE (1991) Functional identification of magnocellular neuroendocrine neurones. In: Neuroendocrine research methods, Vol 2 (Greenstein B, ed), pp 769-791. Chur, Switzerland: Hadwood Academic.

Leng G, Dye S, Bicknell RJ (1997) Kappa-opioid restraint of oxytocin secretion: plasticity through pregnancy. Neuroendocrinology 66:378-383.

Leng G, Brown CH, Russell JA (1999) Physiological pathways regulating the activity of magnocellular neurosecretory cells. Prog Neurobiol $57: 625-655$

Liu H, Terrell ML, Bui V, Summy-Long JY, Kadekaro M (1997) NO and angiotensin II effects on blood pressure and fluid homeostasis. J Neuroendocrinol 9:545-552.

Luckman SM, Huckett L, Bicknell RJ, Voisin DL, Herbison AE (1997) Up-regulation of nitric oxide synthase messenger RNA in an integrated forebrain circuit involved in oxytocin secretion. Neuroscience 77:37-48.
Ludwig M, Leng G (1997) Autoinhibition of supraoptic nucleus vasopressin neurons in vivo: a combined retrodialysis/electrophysiological study in rats. Eur J Neurosci 9:2532-2540.

Montagnese CM, Poulain DA, Theodosis DT (1990) Influence of ovarian steroids on the ultrastructural plasticity of the adult rat supraoptic nucleus induced by central administration of oxytocin. J Neuroendocrinol 2:225-231.

Okere CO, Higuchi T (1996) Down-regulation of endogenous nitric oxide synthase in late-pregnancy and parturition in the rat hypothalamic magnocellular neurons and neurohypophysis. Neurosci Lett 220:133-136.

Okere CO, Higuchi T, Kaba H, Russell JA, Okutani F, Takahashi S, Murata T (1996) Nitric oxide prolongs parturition and inhibits maternal behaviour in rats. NeuroReport 7:1695-1699.

Ozaki M, Shibuya I, Kabashima N, Isse T, Noguchi J, Ueta Y, Inoue I, Shigematsu A, Yamashita H (2000) Preferential potentiation by nitric oxide of spontaneous inhibitory postsynaptic currents in rat supraoptic neurones. J Neuroendocrinol 12:273-282.

Popeski N, Amir S, Woodside B (1999) Changes in NADPH-d staining in the paraventricular and supraoptic nuclei during pregnancy and lactation in rats: role of ovarian steroids and oxytocin. J Neuroendocrinol 11:53-61.

Pow DV (1992) NADPH-diaphorase (Nitric oxide synthase) staining in the rat supraoptic nucleus is activity-dependent: possible functional implications. J Neuroendocrinol 4:377-380.

Renaud LP, Tang M, McCann MJ, Stricker EM, Verbalis JG (1987) Cholecystokinin and gastric distension activate oxytocinergic cells in rat hypothalamus. Am J Physiol 253:R661-R665.

Russell JA, Leng G (1998) Sex, parturition and motherhood without oxytocin? J Endocrinol 157:343-359.

Russell JA, Leng G, Bicknell RJ (1995) Opioid tolerance and dependence in the magnocellular oxytocin system: a physiological mechanism? Exp Physiol 80:307-340.

Sagar SM, Ferriero DM (1987) NADPH diaphorase activity in the posterior pituitary: relation to neuronal function. Brain Res 400:348-352.

Summerlee AJ (1981) Extracellular recordings from oxytocin neurones during the expulsive phase of birth in unanaesthetized rats. J Physiol (Lond) 321:1-9.

Verbalis JG, McCann MJ, McHale CM, Stricker EM (1986) Oxytocin secretion in response to cholecystokinin and food: differentiation of nausea from satiety. Science 232:1417-1419.

Villar MJ, Ceccatelli S, Ronnqvist M, Hokfelt T (1994) Nitric oxide synthase increases in hypothalamic magnocellular neurons after salt loading in the rat. An immunohistochemical and in situ hybridization study. Brain Res 644:273-281.

Vincent SR, Kimura H (1992) Histochemical mapping of nitric oxide synthase in the rat brain. Neuroscience 46:755-784.

Woodside B, Amir S (1996) Reproductive state changes NADPHdiaphorase staining in the paraventricular and supraoptic nuclei of female rats. Brain Res 739:339-342.

Xu D-L, Martin P-Y, St John J, Tsai P, Summer SN, Ohara M, Kim JK, Schrier RW (1996) Upregulation of endothelial and neuronal constitutive nitric oxide synthase in pregnant rats. Am J Physiol 271:R1739-R1745.

Yang QZ, Hatton GI (1999) Nitric oxide via cGMP-dependent mechanisms increases dye coupling and excitability of rat supraoptic nucleus neurons. J Neurosci 19:4270-4279. 